УДК 582.972 .3

DOI 10.18101/2587-7148-2020-1-11-17

\title{
ОСОБЕННОСТИ МОРФОЛОГИИ ПРЕДСТАВИТЕЛЕЙ СЕКЦИИ АРАRINE РОДА GALIUM (RUВIАСЕАЕ) В СВЯЗИ С ВОПРОСАМИ ИХ СИСТЕМАТИКИ
}

\section{Е.А. Пинженина}

(c) Пинженина Екатерина Александровна

Кандидат биологических наук, младший научный сотрудник, Центральный сибирский ботанический сад, ФГБУН СО РАН, Россия, 6303090, г. Новосибирск, ул. Золотодолинская, 101

E-mail: baldk21@ngs.ru

Приводятся морфологические признаки однолетних видов секции Aparine (Rubiaceae). Выявлено, что близкородственные виды Galium aparine L. и Galium vaillantii DC. отличаются опушением стебля под мутовками, опушением верхней стороны листа, формой столбика, длинной тычиночной нити, прикреплением пыльников и особенностями опушения плодов. Показаны основные отличия Galium spurium L. от близких видов.

Ключевые слова: Rubiaceae, Galium, Aparine, морфологический признак, лист, венчик, форма столбика, тычиночная нить, пыльник, фрагмокарпий, мерикарпий, опушение

\section{Для цитирования}

Пинженина E. A. Особенности морфологии представителей секции Aparine рода Galium (Rubiaceae) в связи с вопросами их систематики // Вестник Бурятского государственного университета. Биология, география. 2020. № 1. С. 11-17.

\section{Введение}

Секция Aparine Lange представлена 4 видами. Виды данной секции - однолетние травы со слабыми восходящими, цепляющимися стеблями. У видов по 6-8 листьев с 1 жилкой, собранных в мутовки. Венчики белые, беловатые, зеленовато-белые или желтовато-белые. Плоды (фрагмокарпии) голые или с крючковатыми щетинками. Для видов секции Aparine характерен циркумполярный ареал (занимают территорию Европы, кроме Средиземноморской области, внетропической Азии, Урала, Сибири, Камчатки, Северного Сахалина, Курильских островов, Аляски, большей части Канады). Встречаются в рудеральных местообитаниях, в лесах, на песчаных местах, скалах. На территории Азиатской России секция представлена 3 видами: Galium aparine L., G. spurium L., G. vaillantii DC.

В «Species Plantarum» К. Линней (Linnaei, 1753) привел виды G. spurium и $G$. aparine. Он указал для вида G. spurium наличие голых плодов «fructibus glabris» и отнес этот вид к группе Fructo scabro (Linnaei, 1753). Вид G. aparine Линней охарактеризовал как вид с опушенными плодами (fructibus huspidis) и поместил в группу Fructo hispido (Linnaei, 1753).

A.P. de Candolle во «Flore Fracoise» (Lamarck et de Candolle, 1805) описал новый вид G. vaillantii с простыми стеблями, слабо опушенными мутовками и плодами, покрытыми крючковатыми волосками. De Candolle вид G. spurium, с голыми плодами, поместил в секцию II. Fruit glabre et tuberculeux (Плоды голые, бугорчатые), а виды 
G. aparine и G. vaillantii, с опушенными плодами, в секцию III. Fruit herisse de poils (Плоды с щетинистыми волосками) (Lamarck et de Candolle, 1805).

B «Prodromus systematis naturalis regni vegetabilis» A.P. de Candolle (1830) однолетние виды с зернистыми, щетинисто волосистыми плодами, отнес к группе Euaparines, среди которых отмечены G. aparine, G. spurium, G. vaillantii.

J. Lange (1870) в работе «Prodromus Florae Hispanica» описал секцию Euaparine, к которой отнес однолетние приподнимающиеся травы с шероховатыми стеблями, с пазушными соцветиями. В эту секцию Lange поместил G. spurium и G. aparine и отметил наличие ланцетных листьев, простых цимозных соцветий и опушенных плодов у G. aparine. Для вида G. spurium он указал узкие ланцетно-линейные листья, желто-зеленые венчики и голые плоды. Lange не признал видовой самостоятельности G. vaillantii, но привел его как разновидность G. spurium $\beta$ vaillantii Gren. (Lange,1870).

Е. Г. Победимова (1958) во «Флоре СССР» указала однолетние виды G. aparine и G. spurium. Она отметила, что эти виды отличаются по морфологическим признакам стеблей, листьев, соцветий, венчиков плодов. Вид G. aparine характеризуется опушенным в узлах стеблем, линейно-ланцетными, сидячими листьями с коротко заостренной верхушкой, простыми 2-х, 3-цветковыми, редко 5-цветковыми полузонтиками, белыми венчиками и плодами, опушенными крючковатыми волосками, сидящими на бугорках. Для G. spurium отмечен голый стебель, обратноланцетные листья с черешками и с длинным острием на верхушке, пазушные 6-9-цветковые, редко 3-цветковые полузонтики, зеленовато-желтоватые венчики и плоды, опушенные крючковатыми волосками без бугорков, или голые. Вид G. vaillantii она свела в синонимы к G. spurium.

F. Ehrendorfer (1976) во «Flora Europaea»привел G. spurium и G. aparine. Он указал, что G. spurium и G. aparine различаются высотой стебля (у G. aparine стебли более высокие ((20-)80-180 см) у G. spurium (10-100(-160) см), формой листовой пластинки (листья узкие продолговато-ланцетные, постепенно сужающиеся на верхушке в длинный остистый отросток характерны G. spurium; широкие продолговатоланцетные листья, заостренные на верхушке для G. aparine), размерами и окраской венчика (для G. spurium отмечен венчик 0.8-1.3 мм в диаметре, зеленовато-желтый, у G. aparine - венчик 1.5-1.7 мм, беловатый), плодами (G. spurium имеет густо щетинистые или голые плоды, у G. aparine плоды с плотными крючковатыми щетинками). Вид G. vaillantii Ерендорфер (1976) свел в синонимы к G. spurium, но указал, что виды с голыми и щетинистыми плодами часто произрастают совместно, и отличить их бывает затруднительно.

Обрабатывая род Galium для «Арктической флоры» Н. Н. Цвелев (1987) восстановил G. vaillantii и отличил от близкого G. spurium. Цвелев указал, что $G$. spurium хорошо отличается от G. vaillantii голыми и гладкими плодами. Для $G$. aparine характерны значительно более крупные плоды и крупные беловатые (а не зеленовато-белые как у G. vaillantii) цветки.

В дальнейшем авторы региональных флор (Петелин, 1991; Наумова, 1996) признали видовую самостоятельность G. vaillantii. Д. А. Петелин (1991) указал отличие видов G. vaillantii от G. spurium в наличие густых длинных, крючковато загнутых на концах щетинках на завязях и плодах у G. vaillantii. Для видов родства G. aparine 
E. A. Пинженина Особенности морфологии представителей секции Aparine рода Galium (Rubiaceae) в связи с вопросами их систематики

Е. Г. Наумова (1996) отметила главное отличие в окраске венчика и в опушении плодов. Венчики $G$. aparine - белые, плоды опушены прямыми щетинками с крючком на конце, сидящими на хорошо заметных бугорках. Для вида G. spurium характерны зеленовато-белые венчики и голые плоды, а у G. vaillantii - венчики зеленоватобелые или зеленовато-желтоватые, плоды опушены густыми прямыми щетинками с крючком на конце.

Е. Г. Еленевский $(2000,2003)$ в работах, посвященных роду Galium считал нецелесообразным дифференцировать опушенноплодный вид и применил для него название $G$. aparine.

\section{Цели и задачи}

На протяжении конца XIX века и XX века G. vaillantii не признавался в качестве самостоятельного вида. Во многих региональных «Флорах» и «Определителях» указывались виды G. aparine и G. spurium, описанные Линнеем (Linnaei, 1753), а вид G. vaillantii, описанный De Candolle (1830) приводился только в качестве синонима вида $G$. aparine или разновидности $G$. spurium.

Сложность в разграничении однолетних видов секции Aparine и отсутствие в научной литературе четких морфологических отличий видов родства G. aparine явилось поводом для поиска новых диагностических признаков. Для этих целей нами были критически изучены гербарные коллекции, хранящиеся в Гербариях LE, MHA, MW, NS, NSK, ALTB, TK, IRK, и собственные сборы, проведенные в разных районах Сибири в 2009, 2010, 2011 годах.

Результаты и их обсуждение

Изучение морфологических признаков вегетативных и генеративных органов представителей секции Aparine по всему ареалу показало, что виды G. aparine, G. spurium, G. vaillantii имеют существенные отличия.

Однолетние виды секции Aparine восходящие, цепляющиеся травы, высотой до 1 м., которая варьирует в зависимости от места произрастания вида, имеют длинное корневище. Для этих видов характерен четырехгранный стебель, усаженный по ребрам обращенными вниз крючковатыми шипиками. Однако у всех видов имеется различное опушение стебля под мутовкой. У G. aparine отмечены, как правило, густые жесткие прямые волоски, для $G$. spurium характерны рассеянные прямые волоски, а у G. vaillantii опушение отсутствует. Число листьев в мутовке и морфологические особенности листовой пластинки важные признаки в систематике рода Galium, которые используется для разграничения секций и близких видов. У однолетних видов секции Aparine выявлено 5-8 листьев в мутовке, которые отличаются размерами и формой листовой пластинки. У G. aparine листья (13) 30-45 мм дл., 26 мм шир., продолговато-ланцетные, заостренные на верхушке, сидячие. Листья G. spurium 15-20 (40) мм дл., 1.5-3 (5) мм шир., линейно-ланцетные, заостренные на верхушке, с коротким черешком. Для G. vaillantii характерны листья 9-27 мм дл., 2.5-4.5 мм шир., линейно-обратноланцетные, заканчивающиеся острым шипиком на верхушке, сидячие. По краю листовой пластинке и снизу по жилке видам всем свойственно опушение короткими жесткими крючковатыми шипами, направленными к основанию. Верхняя сторона листа опушена крючковатыми (G. aparine), серповидными (G.spurium) и прямыми, слегка загнутыми на вершине (G. vaillantii) 
шипами (табл.). Соцветие у видов секции Aparine представлено малоцветковыми пазушными полузонтиками, которые часто редуцированы до одиночных цветков. Венчики у однолетних видов колесовидные, 4-лопастные, 11.9 мм диам., белые характерны для вида G. aparine, зеленовато-желтоватые отмечены у G. spurium, зеленовато-белые или зеленовато-желтые у $G$. vaillantii. Родственные виды G. aparine, G. spurium и G. vaillantii хорошо отличаются формой лопастей венчика (табл.). Одним из важных признаков для разграничения близких видов является признак «форма столбика», который разнообразен и стабилен на протяжении всего ареала видов. Выявлено три состояния признака: столбик сросшийся с двумя рыльцами (G. aparine), расщепленный от самого основания (G. spurium), расщепленный от середины (G. vaillantii) (табл.). G. aparine отличается от других видов секции короткими тычиночными нитями и сидячими пыльниками, а не длинными тычиночными нитями и свободными пыльниками как у G. spurium и G. vaillantii. Плод рода Galium называют фрагмокарпием, он является дробным и распадающимся на две части, именуемыми мерикарпиями. Фрагмокарпии у однолетних видов могут быть эллипсоидальные, встречаются у $G$. aparine, округлые или овально-продолговатые отмечены у G. spurium и G. vaillantii. Наиболее крупные плоды наблюдаются у G. aparine 2.0-2.4 мм дл., 2.8-3.4 мм шир., самые мелкие у G. spurium1.0-2.3 мм дл., 1.1-3.0 мм шир., и промежуточного размера у G.vaillantii 1.5-2.6 мм дл., 2.2-3.7 мм шир. Представители секции Aparine отличаются и опушением плодов: опушенные плоды отмечены у видов G. aparine и G. vaillantii, а голые (неопушенные) плоды свойственны только виду G. spurium (табл. 1).

Таблица 1

Основные морфологические признаки представителей секции Aparine

\begin{tabular}{|c|c|c|c|}
\hline \multirow[t]{2}{*}{ Признаки } & \multicolumn{3}{|c|}{ Виды } \\
\hline & G. aparine & G. spurium & G. vaillantii \\
\hline $\begin{array}{l}\text { Форма листовой } \\
\text { пластинки }\end{array}$ & $\begin{array}{l}\text { продолговато-лан- } \\
\text { цетные, заостренные } \\
\text { на верхушке }\end{array}$ & $\begin{array}{l}\text { линейно-ланцетные, } \\
\text { с коротким черешком } \\
\text { заостренные на вер- } \\
\text { хушке }\end{array}$ & $\begin{array}{l}\text { линейно-обратнолан- } \\
\text { цетные, заканчиваю- } \\
\text { щиеся острым шипи- } \\
\text { ком на верхушке }\end{array}$ \\
\hline $\begin{array}{l}\text { Опушение верх- } \\
\text { ней стороны } \\
\text { листовой пла- } \\
\text { стинки }\end{array}$ & $\begin{array}{l}\text { рассеянные, длинные, } \\
\text { крючковатые шипы }\end{array}$ & $\begin{array}{l}\text { рассеянные, } \\
\text { короткие, жесткие, } \\
\text { серповидные шипы }\end{array}$ & $\begin{array}{l}\text { рассеянные, длинные, } \\
\text { мягкие, прямые шипы } \\
\text { со слегка загнутой } \\
\text { вершиной }\end{array}$ \\
\hline Соцветие & (2)3-5-цветковые & 5-7(9)-цветковые & 1-3-цветковые \\
\hline $\begin{array}{l}\text { Венчик: форма } \\
\text { лопастей } \\
\text { венчика }\end{array}$ & продолговатые & $\begin{array}{l}\text { овально- } \\
\text { продолговатые }\end{array}$ & $\begin{array}{l}\text { продолговато- } \\
\text { линейные }\end{array}$ \\
\hline Форма столбика & $\begin{array}{l}\text { сросшийся с двумя } \\
\text { рыльцами }\end{array}$ & $\begin{array}{l}\text { расщепленный от } \\
\text { самого основания }\end{array}$ & $\begin{array}{l}\text { расщепленный } \\
\text { от середины }\end{array}$ \\
\hline $\begin{array}{l}\text { Опушение } \\
\text { плодов }\end{array}$ & $\begin{array}{l}\text { длинные, торчащие, } \\
\text { крючковатые щетинки, } \\
\text { сидящие на бугорках }\end{array}$ & голые & $\begin{array}{l}\text { длинные, торчащие } \\
\text { крючковатые щетинки } \\
\text { без бугорков }\end{array}$ \\
\hline
\end{tabular}


E. A. Пинженина Особенности морфологии представителей секции Aparine рода Galium (Rubiaceae) в связи с вопросами их систематики

Опушенноплодным видам характерны длинные, торчащие щетинки, крючковато загнутые на конце и расширенные у основания (рис. 1). У G. aparine выявлены щетинки, сидящие на бугорках, состоящих из многих выпуклых, грубо складчатых клеток (рис. 1a). Виду G. vaillantii типичны щетинки без бугорков, в основании которых 8(10) плоских, грубо складчатых клеток (рис. 1б). Основные признаки вегетативных и генеративных органов видов G. aparine, G. spurium и G. vaillantii приведены в таблице.

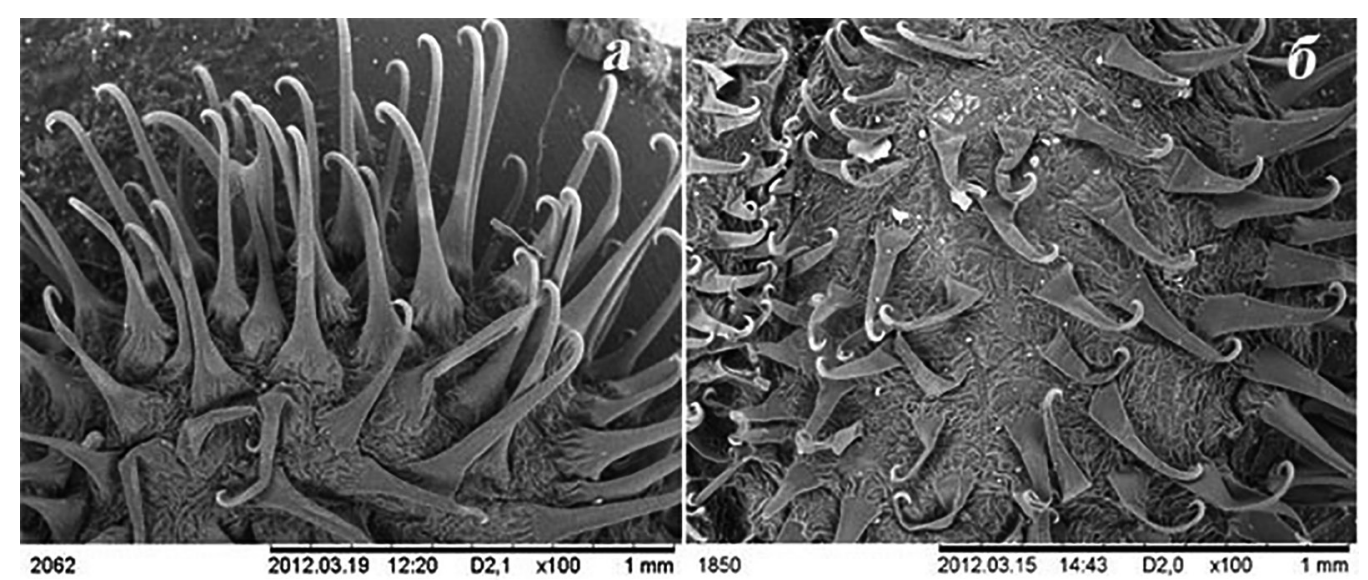

Рис. 1. Форма основания щетинок представителей секции Aparine, $a-G$. aparine, $\sigma-G$. vaillantii. Масштабная линейка: 1 мм.

\section{Заключение}

Проведенные нами исследования показали, что виды G. aparine, G. spurium и G. vailantii отличаются опушением стебля под мутовками, формой листа и опушением его верхней стороны, окраской венчика, формой лопастей венчика, формой столбика и плодами. В научной литературе основным признаком для разграничения близкородственных видов $G$. aparine и $G$. vaillantii указывают особенность опушения плодов (наличие или отсутствие бугорка в основании щетинки). Мной выявлены новые диагностические признаки для их разделения. Виды G. aparine и G. vaillantii отличаются: опушением стебля под мутовкой (опушенные у $G$. aparine, голые у $G$. vaillantii); опушением верхней стороны листа (крючковатые шипы отмечены у $G$. aparine, прямые, слегка загнутые на вершине характерны G. vaillantii); формой столбика (сросшийся у G. aparine, расщепленный от середины у $G$. vaillantii). Кроме того, $G$. aparine отличается от G. vaillantii короткими, а не длинными, тычиночными нитями и сидячими, а не свободными, пыльниками. Главными отличиями G. spurium от предыдущих видов являются голые (неопушенные) плоды, серповидные щетинки на верхней стороне листа и столбик, расщепленный от самого основания.

Диагностические признаки стабильны на всем ареале и могут быть использованы для разграничения близких видов секции Aparine. 


\section{Слова благодарности}

В статье использовался материал Биоресурсной коллекции ЦСБС СО РАН, УНУ «Гербарий высших сосудистых растений, лишайников и грибов (NS, NSK)», № USU440537.

Исследование органов растений проводилось с помощью сканирующего электронного микроскопа Hitachi TM-1000 в ЦКП микроскопического анализа биологических объектов ЦСБС СО РАН.

Работа выполнена в рамках государственного задания ЦСБС СО РАН по проекту АААA-А17-117012610055-3 «Биологическое разнообразие криптогамных организмов (водоросли, грибы, лишайники) и сосудистых растений в геопространстве биотических и абиотических факторов, оченка их роли в водных и наземных экосистемах Северной Азии».

\section{Литература}

1. Еленевский А.Г., Ключникова Н. М., Пятунина С. К. Таксономическая интерпретация изменчивости в комплексе Galium aparine (Rubiaceae) // Бюл. Моск. о-ва испытателей природы. Отд. Биол. 2000. Т. 105. Вып. 3. С. 59-61.

2. Еленевский А. Г., Куранова Н. Г., Пятунина С. К. О секциях в роде Galium L. (Rubiaceae) // Новости сист. высш. раст. 2003. Т. 35. С. 174-187.

3. Наумова Е. Г. Род Galium L. // Флора Сибири. Новосибирск, 1996. Т. 12. С. 110-124.

4. Петелин Д. А. Род Galium L. // Сосудистые растения советского Дальнего Востока. СПб., 1991. Т. 5. С. 212-234.

5. Победимова Е. Г. Род Galium L. // Флора СССР. М., Л., 1958. Т. 23. С. 287-381.

6. Ц Цвелев Н. Н. Род Galium L. // Арктическая флора СССР. Л., 1987. Т. 10. С. 8-23.

7. Candolle A.P. de Gen. Galium L. // Prodromus systematis naturalis regni vegetabilis. Parisiis, 1830. Vol. 4. P. 593-614.

8. Ehrendorfer F., Krendl F. Gen. Galium L. // Flora Europaea. Cambridge, 1976. Vol. 4. P. 14-36.

9. Lamarck M. et Candolle A.P. de Gen. Galium L. // Flore Francaise. Paris, 1805. Vol. 4. P. 248-266.

10. Lange J. Gen. Galium L. // Prodromus florae Hispanica. Stuttgartiae, 1870. Vol. 2. P. 307-327.

11. Linnaei C. Gen. Galium // Species plantarum. Holmiae, 1753. P. 105-108.

FEATURES OF THE MORPHOLOGY OF REPRESENTATIVES

FROM THE SECTION APARINE OF GENUS GALIUM (RUBIACEAE)

IN CONNECTION WITH THE QUESTIONS OF THEIR SYSTEMATICS

\section{E.A. Pinzhenina}

Pinzhenina Ekaterina A.

Candidate of Biological science, Junior Researcher,

Institution of Russian Academy of Science, The Central Siberian Botanical Garden,

The Siberian Branch of the RF Academy of Science

630090, Novosibirsk, Zolotodolinskaya str., 101

E-mail: baldk21@ngs.ru 
Morphological features of annual species of the section Aparine (Rubiaceae) are given. It was revealed that closely related species $G$. aparine and $G$. vaillantii differ in pubescence of the stem under whorls, pubescence of the upper side of the leaf, column shape, long stamen filament, anther attachment and peculiarities of fruit pubescence. The main differences between G. spurium and related species are shown.

Keywords: Rubiaceae, Galium, Aparine, morphological character, leaf, corolla, style shape, anther stalk, anther, fragmocarp, mericarp, pubescence. 